SHKLAR, Judith (2010)

Los rostros de la injusticia.

Traducción de Alicia García Ruiz. Prólogo de Fernando Vallespín

Barcelona: Herder, 200 p.

En un contexto en el que el tema de la justicia está de moda, como puede comprobarse por el éxito editorial del libro de Michel J. Sandel Justícia ¿'hacemos lo que debemos? no está de más que aparezca un libro que hable de la injusticia, como el que nos ocupa. Porque no es evidente, como dice la autora del libro, el planteamiento platónico de que una vez definimos la justicia sabremos por deducción lo que es la injusticia. Porque si el intento de decir lo que es la justicia es necesariamente racional y abstracto, la experiencia de la injusticia es inmediata, directa y emocional.

De hecho, otro éxito de ventas, el libro de Stephan Hessel Indignaos habla de este sentimiento moral cuando captamos algo injusto. El mismo Michel Foucault, que tanto criticó la idea abstracta de justicia, acabó defendiendo los derechos humanos en nombre de la necesidad de reaccionar contra lo insoportable. En todo caso, tanto Hessel como Foucault defienden la necesidad de resistirse a la injusticia sin necesidad de definir lo que es la justicia. En contra de lo que planteaba gente como Althusser no hay que ver en esta reacción primaria una expresión de la ideología, sino una muestra de que los humanos tenemos un sentimiento moral común que hay que preservar y alimentar en contra de los relativismos y comunitarismos.

Judith Shklar, nacida en el año 1928 y muerta prematuramente a los 64 años, tiene el mérito de abordar el tema de la injusticia desde una reflexión basada en su experiencia personal. Nacida en Letonia de familia judía, tuvo una juventud nómada marcada por la persecución, que le llevó de Suecia a Canadá pasando por Japón. Finalmente se instaló en EE.UU., donde desarrolló una brillante carrera académica y acabó como primera presidenta de la Asociación Americana de Ciencia Política. Ella se califica a sí misma con una expresión poco sugerente, que es la del liberalismo del miedo. El valor de utilizar un adjetivo tan poco atractivo da muestra de su sinceridad y libertad intelectual. Está claro que ella no busca aplausos ni hace guiños a la galería sino que se plantea muy seriamente una forma rigurosa de analizar el fenómeno de la injusticia diferenciándolo del de la justicia. Como he comentado antes, hay un componente emocional en la injusticia que la aparta de concepciones normativistas y legalistas. No son las leyes ni las normas las que evitarán la injusticia, aunque evidentemente son necesarias. Pero para desarrollar un análisis en profundidad de las raíces y de los rostros de la injusticia hay que hacer un análisis más complejo. Hay que abordar las instituciones y las actitudes y las conductas humanas, no solamente las leyes. Esto en EE.UU. (y no hay que olvidar que aunque su alcance sea más amplio, éste es el contexto) es muy claro: un país puede discriminar racialmente o sexualmente incluso si sus leyes son igualitarias. Hay una diferencia clara cuando tratamos la injusticia entre lo que es subjetivo (actitudes, sentimientos) y lo que es objetivo (normas, instituciones), pero ambos están entrelazados y no podemos tampoco separarlos.

El libro plantea muchas y muy interesantes cuestiones. Dos de ellas son las que desmontan dos tópicos: «La naturaleza es injusta" $\mathrm{y}$ "Todos somos culpables». Empezaremos por el primero, y la base crítica será la diferencia entre injusticia y desventura. Esta última es producto de un desastre natural y podríamos actualizarlo con un ejemplo diferente del 
que se utiliza en el libro, que sería el de los terremotos. Es sugerente la analogía entre el drama y la tragedia. Esta última, vinculada a una concepción más antigua, plantea el carácter irremediable de los males humanos, que se ven entonces más como una desventura que como una injusticia. Aquí las religiones han tenido el nefasto papel de presentar como naturales o causadas por la Voluntad Divina injusticias humanas con responsables claros que lo que han hecho es salvaguardar sus privilegios a costa del sufrimiento colectivo. Pero aquí entran también los matices que la autora señala, que es que es una responsabilidad humana el prevenirlos y, en su caso, el paliarlos. Judith Shklar es una liberal con sensibilidad social y esto le hace evidenciar la diferencia entre la responsabilidad de los que gestionan las instituciones y el resto de los mortales. Con esto enlazamos con la siguiente crítica a la generalización de la culpa. Es preciso delimitar las responsabilidades porque de esta manera lo hacemos también con las culpas. Cuando Jean Genet, hace muchas décadas, criticaba a los que se escandalizaban por los atentados terroristas palestinos diciendo que todos éramos culpables de su situación, lo que hacía era diluir las responsabilidades. Aunque tampoco podemos contentarnos con dar la culpabilidad a los agentes directos cuando somos espectadores pasivos, como muy bien recalca la autora del libro. El tema es complejo y lleno de matices y una de las virtudes del libro es no obviarlos para encontrar una respuesta simple. Judith Sklar, por otra parte, recurre a una tradición que no es la anglosajona, como ponen de manifiesto sus constantes referencias a Montaigne y Rousseau. Otros temas que aparecen en el estudio son el de la venganza, tema poco tratado en filosofía moral y política (una excepción es Paul Ricouer) y que como bien señala la autora remite básicamente a Nietzsche y su Genealogía de la moral. Insiste básica- mente en la consideración de la víctima, fundamental dentro de un sentido reparador de la justicia aunque quizás hoy habría que revisar constatando los peligros de una sociedad victimista. No comparto, por el contrario, la reticencia de Judith Shklar delante de la noción de justicia distributiva y su sustitución por justicia primaria, que me parece aún más ambigua.

Entraré finalmente en las implicaciones políticas de la opción de Judith Sklar. Esta reflexión se dificulta enormemente por la confusión que acompaña hoy al término liberalismo, profundamente desacreditado por el neoliberalismo económico. Lo primero que hay que decir es que el liberalismo de Judith Shklar es un liberalismo social, preocupado por las desigualdades sociales. Hace una crítica explícita y radical de los que en su época lo defendieron, como es el caso de Haydeck, que defiende el mercado y la competencia como el orden económico natural y que teoriza a partir de aquí que sus efectos negativos son más desventuras que injusticias. Lo que distingue su liberalismo es la defensa de la libertad personal y sobre todo su resistencia a los efectos de la crueldad humana como causa del sufrimiento. En este sentido podría estar en la línea de John Stuart Mill, aunque éste resalte más el segundo aspecto y la autora el primero. Judith Shklar es escéptica respecto a la condición humana (aunque sin llegar a planteamientos como el de Hobbes, al que critica en profundidad en sus opciones políticas) y esto le lleva a centrarse más en los vicios a evitar que en las virtudes a potenciar. Se sitúa por tanto en la defensa de la libertad negativa y cuestiona, como dice el buen prólogo de Fernando Vallespín, las concepciones democráticas-republicanas basadas en el desarrollo de la participación política y las virtudes públicas. Ella no es una hipócrita como muchos liberales que se llaman demócratas sin serlo para encajar en el discurso políticamente correcto. Libe- 
ralismo y democracia no son lo mismo, nos dice, pero son un matrimonio de conveniencia. En todo caso aunque sea más liberal que democrática está claro que no es por razones elitistas sino más bien escépticas. Ella no desconfía de las masas para fiarse de las élites sino que sencillamente no contempla esta diferencia. Quizás sería interesante comparar su teoría de la democracia con la de Chantal Mouffe, que insiste en la necesidad de contemplar las pasiones humanas y ver la democracia como un escenario para

MiLnER, Jean-Claude (2005)

\section{La politique des choses}

París: Navarin Editeur

L'any 2003 es produeix a França un terrabastall important entre la "petita burgesia intel-lectual». Aquest terrabastall esdevindrà amb el temps «una novetat en el control social» sota el significant «avaluació». Heus aquí el punt d'arrencada de l'anàlisi de Milner sobre «la política de les coses».

El 8 d'octubre del 2003 els parlamentaris francesos de dreta i d'esquerres voten un text (l'amendement Accoyer) que pretén controlar les així anomenades "professions psy" arreu del país. Segons Milner, aquest fet no tindria, en si mateix, gaire abast històric. Sí, en canvi, tindrà abast històric la batalla que desencadenà en la defensa de la llibertat de pensament: d'aquesta manera s'engegà una mobilització que mogué la burgesia intel.lectual per primera vegada per causa sui. La decepció per l'esquerra fou immensa: la petita burgesia, que havia «llançat tots els moviments importants, des de 1789 fins a 1968, mesurà la seva humiliació» (Milner: 9) L' «esmena» Accoyer revelà un fet flagrant: que les mesures legislatives podien ser no únicament injustes sinó també basades en els prejudicis. En el cas d'Accoyer, els prejudicis contra resolver los conflictos sin negarlos ni planearse la eliminación del contrario.

Es, en conclusión, una lectura recomendable, más interesante en algunas partes que otras, pero que en todo caso nos permite pensar sobre un tema, el de la injusticia, que pocos han tratado con su rigor.

Luis Roca Jusmet

Universitat Autònoma de Barcelona

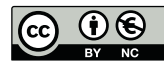

la psicoanàlisi $\mathrm{i}$ «qualsevol altre discurs que se n'autoritzi» (pàg. 6).

Milner aprofita els fets legislatius del 2003 i les protestes que se'n derivaren per generar una anàlisi de la crisi de la política a partir del problema de l'avaluació, definit no pas com una paraula sinó com un imperatiu (un mot d'ordre) en la política. "L'avaluació dels avaluadors no indica un concepte, sinó una pràctica d'aparell; no és interna al saber teòric, sinó externa; no requereix cap saber determinat, ni teòric ni empíric» (pàg. 10). Hi ha, en el funcionament social i polític de l'avaluació, una dimensió que esbirra el diàleg social i converteix el govern en un govern de coses. La crítica de Milner, com sempre, és punyent i colpidora:

"De fet, la ideologia de l'avaluació serveix per a tot, amb la condició de no sortir-ne. Serveix fidelment tant els defensors més aferrissats del liberalisme econòmic com les tendres ànimes humanistes, somniadores d'una distribució ètica i justa; tan aviat manté els privilegis adquirits com també prepara les reformes més imprudents. (...) Però més enllà d'això, projecta intervenir fins al més íntim i més secret de la vida dels individus. No ens 